\title{
Penfigoide bolhoso: relato de caso
}

Isabel Maria Gama Simões, ${ }^{1}$ Olga Ferreira²

\section{RESUMO}

Introdução: O penfigoide bolhoso é a dermatose bolhosa autoimune mais comum na Europa Ocidental. É uma doença crónica, com exacerbações espontâneas e remissões e, consequentemente, significativa morbilidade.

Descrição do caso clínico: Doente do sexo masculino, 77 anos, pertencente a uma família nuclear de classe social média baixa, com antecedentes de diabetes mellitus tipo 2, hipertensão arterial, obesidade e hiperplasia benigna da próstata. O doente foi observado no serviço de urgência por erupção cutânea pruriginosa nos membros superiores com dez dias de evolução, posteriormente com atingimento do tronco e membros inferiores, sem melhoria apesar da terapêutica prévia com bilastina. A medicação instituída foi flucloxacilina, ciprofloxacina, deflazacorte, cloridrato de hidroxizina e aplicação tópica de emoliente, tendo alta com indicação para avaliação por dermatologia. Na observação em consulta de dermatologia apresentava bolhas tensas de conteúdo sero-hemático sobre placas eritematosas na região inguinal e nos membros inferiores, com sinal de Nikolsky negativo. Nos membros superiores e tronco observavam-se lesões urticariformes confluentes e lesões crostosas nas regiões flexoras dos membros superiores. Colocada a hipótese de diagnóstico de penfigoide bolhoso, foi realizada biópsia de bolha recente, suspensão da terapêutica anterior, prescrição de prednisolona oral, betametasona pomada e ácido fusídico pomada tópicos, ranitidina oral, dieta, controlo das glicemias e estudo analítico. Na consulta de reavaliação, o doente não apresentava lesões de novo e a dose de prednisolona foi gradualmente reduzida. O exame histológico confirmou o diagnóstico de penfigoide bolhoso.

Comentário: O diagnóstico precoce do penfigoide bolhoso é crucial e a medicina geral e familiar possui uma posição privilegiada para a sua abordagem inicial e referenciação atempada.

Palavras-chave: Penfigoide bolhoso; Bolha subepidérmica; Prednisolona.

\section{INTRODUÇÃO}

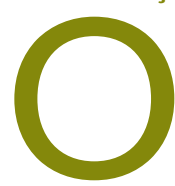

penfigoide bolhoso (PB) é a dermatose bolhosa autoimune mais comum na Europa Ocidental. ${ }^{1-2}$ Esta doença afeta tipicamente idosos, embora surja raramente em crianças e adultos jovens, ${ }^{1,3-5}$ com predomínio no sexo masculino. ${ }^{2,4}$ Recentemente, o PB foi associado a doenças neurológicas como a doença cerebrovascular, demência, doença de Parkinson, epilepsia e esclerose múltipla. ${ }^{1-2}$ Não há evidência conclusiva sobre a associação com doenças malignas ou outras doenças autoimunes. ${ }^{1}$ Os fármacos com alguma associação com esta patologia são: furosemida, espironolactona, metformina+gliptinas e alguns neurolépticos. ${ }^{1-2}$

O PB é uma doença crónica, com exacerbações espontâneas e remissões e, consequentemente, significativa morbilidade. $^{2}$

1. Unidade de Cuidados de Saúde Personalizados de Caminha. 2. Serviço de Dermatologia e Venereologia, Hospital de Braga.

\section{DESCRIÇÃO DO CASO \\ Identificação}

Doente do sexo masculino, 77 anos de idade, raça caucasiana, casado, reformado, com profissões anteriores de pedreiro e carpinteiro. Elemento de uma família nuclear, com índice de Graffar correspondente a classe social média baixa, na fase VII do ciclo de vida familiar de Duvall.

\section{Antecedentes pessoais e familiares}

Antecedentes pessoais de diabetes mellitus tipo 2, hipertensão arterial, obesidade e hiperplasia benigna da próstata, estando medicado habitualmente com metformina+vildagliptina, gliclazida, ibersartan+hidroclorotiazida e dutasterida. Sem alteração recente da medicação habitual ou história anterior de alergias.

Sem antecedentes familiares relevantes.

\section{História da doença atual}

Em agosto de 2013, o doente foi observado no serviço de urgência (SU) do hospital da sua área de residência por erupção cutânea pruriginosa nos membros superiores 
com 10 dias de evolução, posteriormente com atingimento do tronco e membros inferiores, sem outra sintomatologia associada e sem melhoria, apesar da terapêutica com bilastina duas vezes por dia instituída nos cuidados de saúde primários. Ao exame físico não apresentava outras alterações. No estudo analítico registou-se hiperglicemia (360mg/L) e hiponatrémia (129mmol/L) com necessidade de correção. Também foi realizada a administração de hidrocortisona 200mg endovenosa. O doente teve alta para ambulatório com indicação para avaliação em consulta de dermatologia do Hospital de Braga, tendo sido medicado com: flucloxacilina 500mg de 8 em 8 horas, ciprofloxacina 500mg de 12 em 12 horas durante oito dias, deflazacorte 30mg segundo esquema terapêutico, cloridrato de hidroxizina $25 \mathrm{mg}$ e aplicação tópica de emoliente.

Decorrida uma semana, o doente foi referenciado pelo seu médico de família para o SU do hospital de referência, devido a agravamento progressivo das queixas apesar da terapêutica instituída, sendo referido que estas surgiram após picada de artrópode hymenoptera (abelha) no membro superior direito. À observação apresentava bom estado geral, erupção bolhosa muito pruriginosa de predomínio nos membros inferiores, poupando a face, palmas e plantas, sem atingimento das mucosas. Analiticamente apresentava leucocitose e aumento da proteína $\mathrm{C}$ reativa. O serviço de dermatologia dessa instituição foi contactado, sendo dada indicação para avaliação em consulta muito prioritária de dermatologia. A terapêutica instituída foi mantida.

No dia seguinte, na observação realizada na consulta de dermatologia, o doente apresentava lesões bolhosas tensas de conteúdo sero-hemático sobre placas eritematosas na região inguinal e nos membros inferiores (Figuras 1 e 2), com sinal de Nikolsky negativo. Nos membros superiores e tronco apresentava lesões urticariformes confluentes (Figuras 1 e 3) e lesões crostosas nas regiões flexoras dos membros superiores (Figura 4). Colocada a hipótese de diagnóstico de PB, foi realizada biópsia de bolha recente e instituído o seguinte plano terapêutico:

- Suspensão da terapêutica anterior.

- Prednisolona 60mg por dia durante quatro dias, posteriormente $50 \mathrm{mg}$ por dia.

- Betametasona pomada, duas aplicações diárias nas bolhas.

- Ácido fusídico pomada, duas aplicações diárias nas erosões e lesões crostosas.

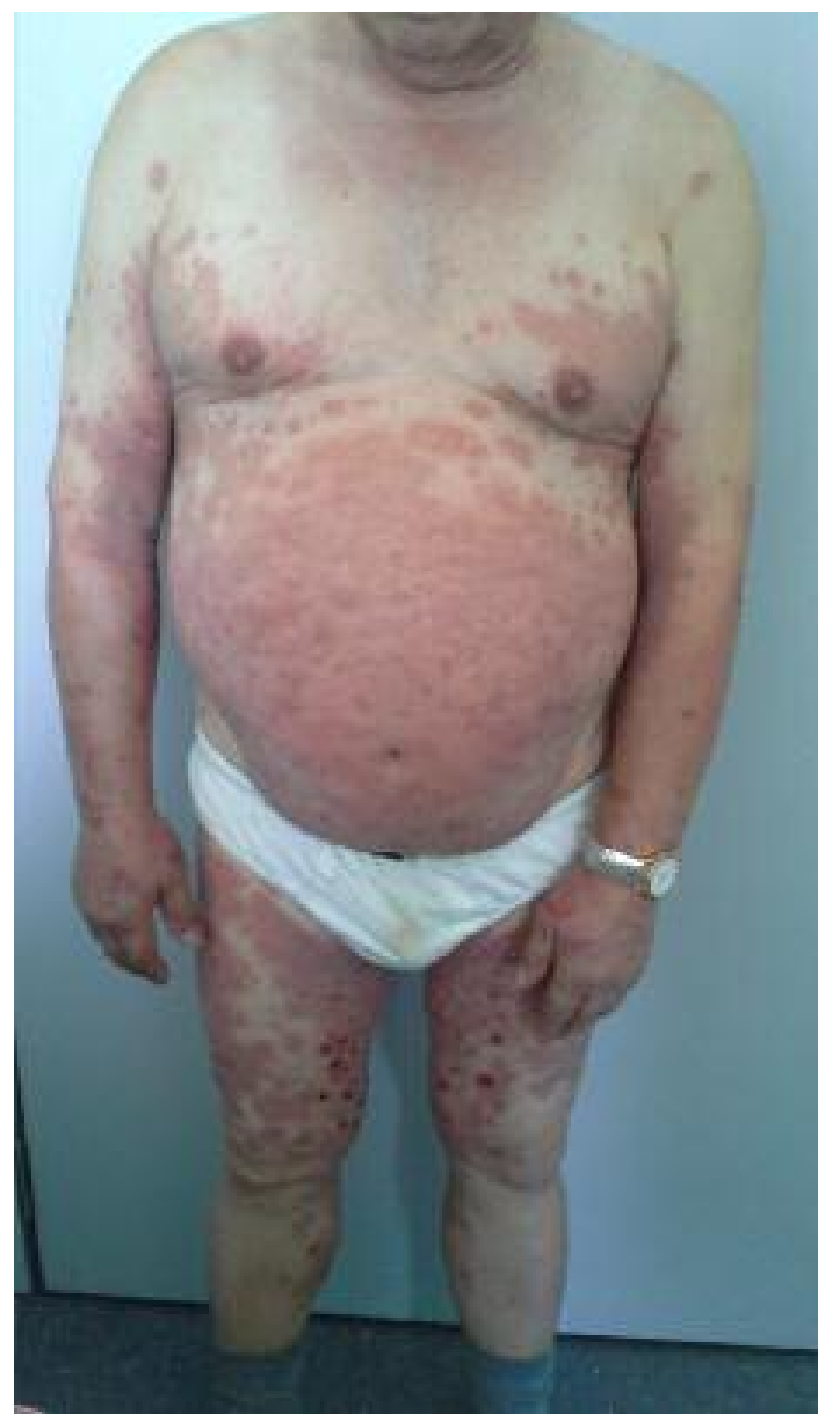

Figura 1. Bolhas tensas sobre placas eritematosas na região inguinal e membros inferiores. Lesões urticariformes confluentes nos membros superiores e tronco.

- Ranitidina $150 \mathrm{mg}$, um comprimido ao jantar.

- Dieta e controlo das glicemias antes das principais refeições.

- Requisição de estudo analítico.

Após uma semana, na segunda consulta de dermatologia, o doente mantinha bolhas na região inguinal, mas sem aparecimento de novas lesões. O resultado do exame histológico não estava disponível. Analiticamente de referir hiperglicemia $(273 \mathrm{mg} / \mathrm{dl})$ e hipertrigliceridemia (229mg/dl). O plano terapêutico foi ajustado, sendo reduzida a prednisolona para $40 \mathrm{mg}$ por dia, mas a tera- 


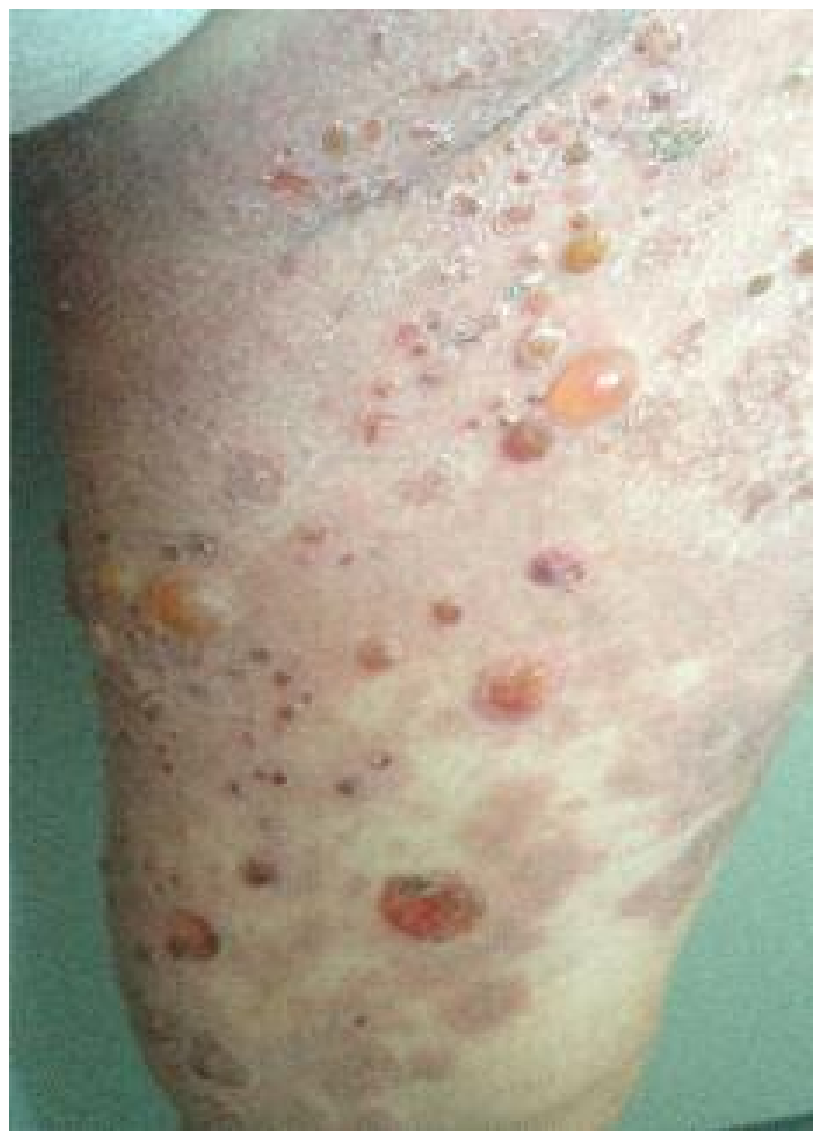

Figura 2. Maior ampliação das lesões na região inguinal e membros inferiores.

pêutica tópica foi mantida. $\mathrm{O}$ doente foi aconselhado a ser avaliado pelo seu médico de família, mantendo o seguimento em dermatologia.

O resultado do exame histológico do retalho de pele da coxa com bolha de um centímetro revelou bolha dermoepidérmica, em cujo interior se identificou exsudado seroso e células inflamatórias com predomínio de polimorfonucleares eosinófilos. Na derme papilar observou-se também infiltrado inflamatório com presença de frequentes polimorfonucleares eosinófilos. Em conclusão, este resultado confirmou o diagnóstico de penfigoide bolhoso.

\section{COMENTÁRIO}

O penfigoide bolhoso é uma doença bolhosa autoimune subepidérmica, na qual a formação de bolhas subepidérmicas é provocada pela presença de autoanticorpos, mais frequentemente do tipo IgG, contra componentes da membrana basal, os hemidesmossomas, que promovem

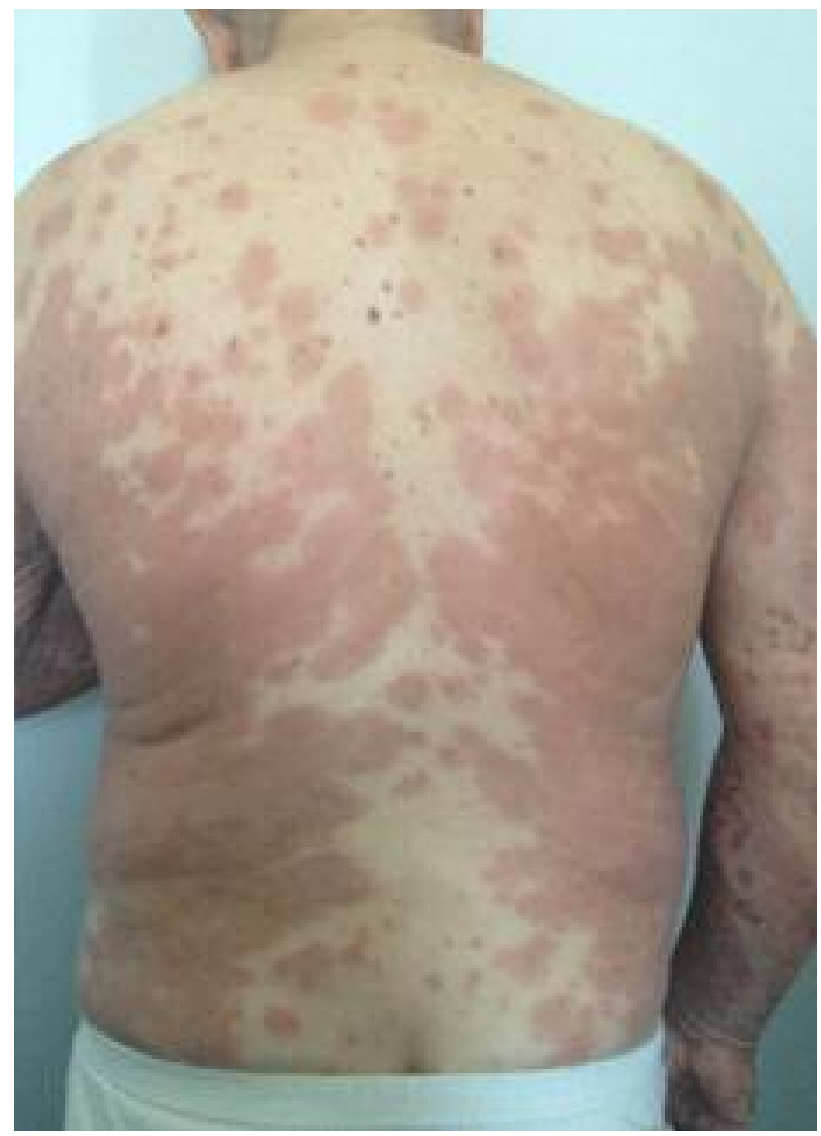

Figura 3. Lesões urticariformes confluentes nos membros superiores e tronco.

a coesão dermo-epidérmica. ${ }^{1-3,6} \mathrm{O}$ prurido isolado ou associado a eritema e/ou placas urticariformes pode preceder a formação de bolhas por semanas ou meses. ${ }^{1-2,6} \mathrm{Ge}-$ ralmente, ao exame físico observam-se bolhas tensas com um a quatro centímetros de diâmetro sobre base eritematosa ou pele aparentemente normal, de conteúdo seroso ou ocasionalmente hemático, difusas ou localizadas, nos membros e tronco, frequentemente com distribuição simétrica. ${ }^{1-2,5}$ Os sinais de Nikolsky e Asboe-Hansen são negativos. ${ }^{6}$ Posteriormente, áreas erosivas e/ou cobertas por crostas podem surgir. ${ }^{2,4-5} \mathrm{As}$ bolhas e as erosões podem atingir a mucosa oral (10 a 30\% dos casos) e/ou genital..$^{2-3,5} \mathrm{Em}$ alguns casos, as bolhas podem não ser clinicamente visíveis. ${ }^{4} \mathrm{O}$ prurido pode ser moderado a severo intratável. ${ }^{4}$

\section{Diagnóstico diferencial}

Como os achados clínicos na fase não bolhosa do PB podem ser inespecíficos, este pode assemelhar-se a uma 


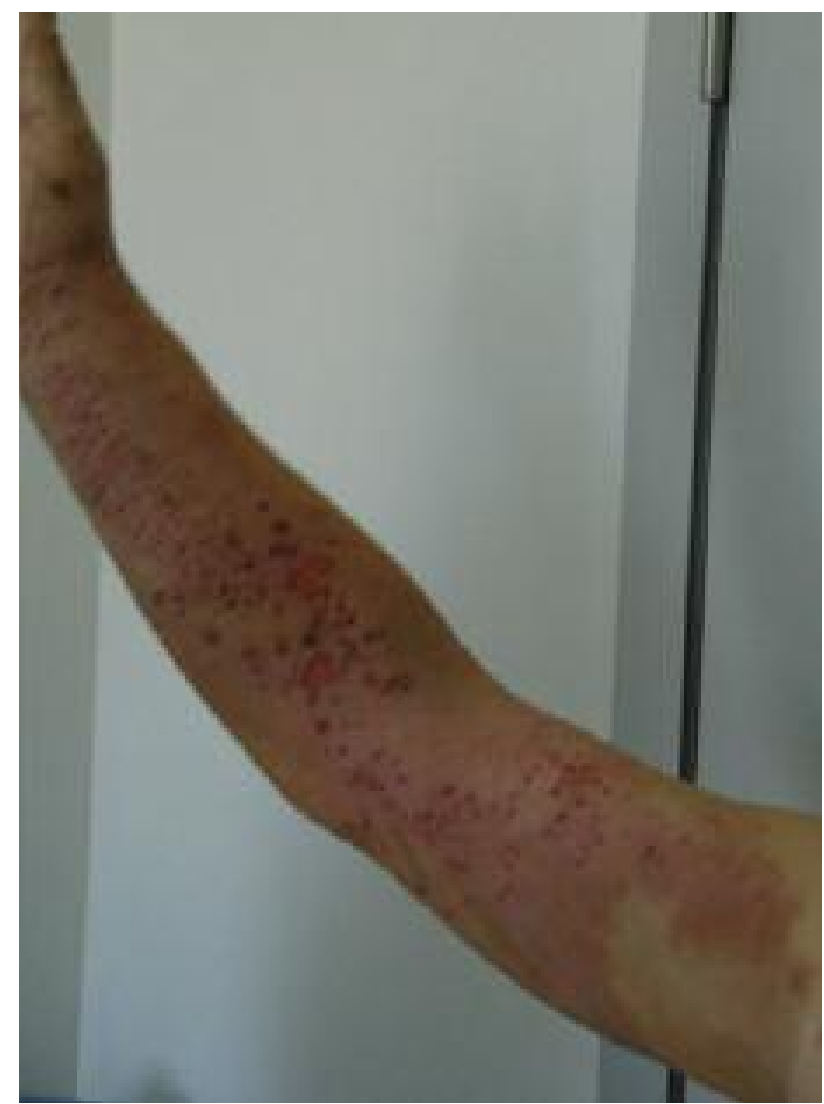

Figura 4. Lesões crostosas nas regiões flexoras dos membros superiores.

variedade de dermatoses, como a reação adversa a fármacos, dermatite de contacto, prurigo, reação a artrópodes e escabiose. ${ }^{2}$ As doenças autoimunes bolhosas podem sobrepor-se na morfologia e imunopatologia; no entanto, fatores como a idade de apresentação, curso da doença, ausência de cicatrizes e atrofia, extensão do envolvimento mucoso e locais de envolvimento são importantes para diferenciar o diagnóstico. ${ }^{1} \mathrm{O}$ diagnóstico do PB baseia-se na apresentação clínica típica, nas características histológicas e, o mais importante, nos achados positivos na imunofluorescência. ${ }^{1} \mathrm{~A}$ biópsia de bolha recente corada com hematoxilina e eosina revela bolha subepidérmica e um infiltrado inflamatório constituído principalmente por eosinófilos, sendo o diagnóstico confirmado por imunofluorescência. ${ }^{1-5} \mathrm{O}$ Enzyme-Linked Immunosorbent Assay (ELISA) permite dosear os títulos dos anticorpos, o BPAg2 é o mais sensível e os seus títulos correlacionam-se com atividade da doença. ${ }^{1-4} \mathrm{O}$ estudo por imunofluorescência é fundamental para o diagnóstico diferencial com outras dermatoses bolhosas autoimunes, principalmente as subepidérmicas como a dermatose bolhosa linear de IgA, penfigoide cicatricial e epidermólise bolhosa adquirida. ${ }^{1-4}$

\section{Tratamento}

O objetivo do tratamento é o controlo sintomático com o mínimo possível de efeitos adversos. ${ }^{1}$ A decisão depende das circunstâncias individuais do paciente, particularmente da severidade do PB e da presença de comorbilidades. ${ }^{1}$

Os corticosteroides sistémicos são o melhor tratamento estabelecido (Força de Recomendação A), com supressão da inflamação e das bolhas em uma a quatro semanas. ${ }^{1-2}$ As doses de prednisolona recomendadas são 0,75 $1 \mathrm{mg} / \mathrm{kg} /$ dia na doença severa, $0,5 \mathrm{mg} / \mathrm{kg} /$ dia na doença moderada e $0,3 \mathrm{mg} / \mathrm{kg} /$ dia na doença ligeira ou localizada. ${ }^{1}$ A proteção gástrica está recomendada, assim como a minimização da perda de densidade óssea, principalmente em mulheres pós-menopausa, homens com mais de 50 anos, casos de risco aumentado de fratura de fragilidade e doses previstas de prednisolona superiores a 7,5mg/dia pelo menos durante três meses. ${ }^{1}$ Os efeitos adversos metabólicos e imunossupressores severos ocorrem e são dose-dependente. ${ }^{1} \mathrm{O}$ aumento da dose para além de $1 \mathrm{mg} / \mathrm{kg} /$ dia tem mais toxicidade com pouco benefício. ${ }^{1}$

Os corticosteroides tópicos, quando factíveis, devem ser considerados a terapêutica de primeira linha (Força de Recomendação A), principalmente na doença localizada e moderada. ${ }^{1,6} \mathrm{O}$ propionato de clobetasol parece ter menos efeitos adversos que a prednisolona na dose de $1 \mathrm{mg} / \mathrm{Kg} /$ dia. $^{1} \mathrm{O}$ seu uso na doença extensa pode ser limitado por razões práticas e pode estar associado a absorção sistémica e efeitos adversos. ${ }^{1,6}$

Outros tratamentos como azatioprina, antibióticos anti-inflamatórios, metotrexato, micofenolato de mofetil, ciclofosfamida, clorambucilo, rituximab, entre outros, podem ser considerados. ${ }^{1-3,6}$

\section{Evolução}

Habitualmente, a evolução do PB é autolimitada, mas a fase ativa está associada a significativa morbilidade e mortalidade. ${ }^{1-2,6}$ As complicações em doentes não tratados incluem infeções cutâneas, desidratação, desequilíbrio eletrolítico e possivelmente morte por sepsia. ${ }^{6} \mathrm{~A}$ ida- 
de avançada na apresentação inicial e as comorbilidades são os fatores de pior prognóstico. ${ }^{1,3,6}$

O PB associa-se a significativa morbilidade, com profundo impacto na qualidade de vida, sendo o seu diagnóstico precoce crucial. A medicina geral e familiar, através da prestação de cuidados de saúde primários, pelo seu caráter preventivo e holístico que tão bem a caracteriza, encontra-se numa posição privilegiada para a abordagem inicial dos doentes com PB e, consequentemente, para a sua referenciação atempada para os cuidados de saúde secundários. O diagnóstico tardio desta patologia ocasiona repercussões significativas na qualidade de vida dos doentes, contribuindo para um pior prognóstico.

De salientar a relevância da acessibilidade aos cuidados de saúde primários e da existência de uma articulação rápida, adequada e eficaz entre estes e os cuidados de saúde secundários.

\section{AGRADECIMENTOS}

À Dra. Maria da Luz Duarte, responsável do estágio hospitalar de Dermatologia e Venereologia, pelo apoio prestado na elaboração do presente artigo.

\section{REFERÊNCIAS BIBLIOGRÁFICAS}

1. Venning VA, Taghipour K, Moud Mustapa MF, Highet AS, Kirtsching G.
British Association of Dermatologists' guidelines for the management of bullous pemphigoid 2012. Br J Dermatol. 2012;167(6):1200-14.

2. Bolognia JL, Jorizzo JL, Schaffer JV. Dermatolology (Vol. 1). 3rd ed.Washington: Elsevier Saunders; 2012. ISBN 9780723435716

3. Silva MR, Castro MC. Fundamentos de dermatologia (Vol. 1). Rio de Janeiro: Atheneu; 2009. ISBN 9788573792133

4. Leiferman KM. Clinical features and diagnosis of bullous pemphigoid and mucous membrane pemphigoid. UpToDate.com; 2018 [cited 2013 Sep 3; updated 2017 Nov 7]. Available from: https://www.uptodate. com/contents/clinical-features-and-diagnosis-of-bullous-pemphigoidand-mucous-membrane-pemphigoid\#subscribeMessage

5. Sousa B, Mota A, Morgado H, Lopes JM, Dias JM. Penfigóide bolhoso em lactente [Bullous pemphigoid in an infant]. Acta Med Port. 2005;18 (2):159-62. Portuguese

6. Goldsmith LA, Katz SI, Gilchrest BA, Paller AS, Leffell DJ, Wolff K. Fitzpatrick's dermatology in general medicine (Vol. 1). 8th ed. Washington: McGraw Hill; 2012. ISBN 9780071669054

\section{CONFLITO DE INTERESSES}

As autoras declaram não ter quaisquer conflitos de interesse.

\section{ENDEREÇO PARA CORRESPONDÊNCIA}

Isabel Maria Gama Simões

E-mail: imgsimoes@hotmail.com

Recebido em 30-08-2016

Aceite para publicação em 31-01-2018

\section{ABSTRACT}

\section{BULLOUS PEMPHIGOID: A CASE REPORT}

Introduction: Bullous pemphigoid is the most common autoimmune bullous dermatosis in Western Europe. It is a chronic disease with spontaneous remissions and exacerbations and, consequently, significant morbidity.

Case description: 77-year-old male patient, from a low-middle class nuclear family, with a history of type 2 diabetes mellitus, hypertension, obesity, and benign prostatic hyperplasia. The patient was observed at the emergency department due to an itchy rash on the upper limbs evolving over 10 days, which further generalised to the trunk and lower limbs, and without improvement despite previous treatment with bilastine. The therapeutic prescribed included flucloxacillin, ciprofloxacin, deflazacort, hydroxyzine hydrochloride and topic emollient, and the patient was discharged and referred to Dermatology. At the Dermatology appointment, the patient exhibited bullous lesions with serohematic content on erythematous plaques in the inguinal region and lower limbs, with negative $\mathrm{Ni}$ kolsky's sign. Confluent urticarial lesions were observed in the upper limbs and trunk, as well as crustal lesions in the flexor regions of the upper limbs. Based on the diagnostic hypothesis of bullous pemphigoid, a biopsy of a blister was performed, and prior therapy was suspended and replaced by oral prednisolone, topical betamethasone, topical fusidic acid, oral ranitidine, diet, glucose monitoring, and laboratory analysis. At follow-up, the patient did not exhibit de novo lesions, and the dose of prednisolone was gradually reduced. Histological examination confirmed the diagnosis of bullous pemphigoid.

Commentary: Early diagnosis of bullous pemphigoid is crucial and family physicians hold a privileged position for its initial management and timely referral.

Keywords: Bullous pemphigoid; Subepidermal blister; Prednisolone. 